\title{
A paradigm linking herpesvirus immediate-early gene expression apoptosis and myalgic encephalomyelitis chronic fatigue syndrome
}

This article was published in the following Dove Press journal:

Virus Adaptation and Treatment

2I February 20II

Number of times this article has been viewed

\author{
A Martin Lerner' \\ Safedin Beqaj ${ }^{2}$ \\ 'Department of Medicine, \\ William Beaumont Hospital, \\ Royal Oak, MI, USA; \\ ${ }^{2}$ DCL Medical Laboratories, \\ Indianapolis, IN, USA
}

Correspondence: A Martin Lerner 32804 Pierce Rd, Beverly Hills, MI 48025, USA

Tel +I 2485409866

$\mathrm{Fax}+\mathrm{I} 2485400139$

Email amartinlerner@yahoo.com

\begin{abstract}
There is no accepted science to relate herpesviruses (Epstein-Barr virus [EBV], human cytomegalovirus [HCMV], and human herpesvirus 6 [HHV6]) as causes of myalgic encephalomyelitis (ME)/chronic fatigue syndrome (CFS). ME/CFS patients have elevated serum immunoglobulin (Ig)G serum antibody titers to EBV, HCMV, and HHV6, but there is no herpesvirus DNA-emia, herpesvirus antigenemia, or uniformly elevated $\operatorname{IgM}$ serum antibody titers to the complete virions. We propose that herpesvirus EBV, HCMV, and HHV6 immediate-early gene expression in ME/CFS patients leads to host cell dysregulation and host cell apoptosis without lytic herpesvirus replication. Specific antiviral nucleosides, which alleviate ME/CFS, namely valacyclovir for EBV ME/CFS and valganciclovir for HCMV/ HHV6 ME/CFS, inhibit herpesvirus DNA polymerases and/or thymidine kinase functions, thus inhibiting lytic virus replication. New host cell recruitment thus ceases. In the absence of new herpesvirus, nonpermissive herpesvirus replication stops, and ME/CFS recovery ensues.
\end{abstract}

Keywords: ME/CFS, Epstein-Barr virus (EBV), human cytomegalovirus (HCMV), HHV6, abortive replication

The gamma herpesvirus Epstein-Barr virus (EBV) and both beta herpesviruses human cytomegalovirus (HCMV) and human herpesvirus 6 (HHV6) have biphasic life-cycles of replication and latency during which these large virus genomes are expanded or maintained, respectively. ${ }^{1}$ During virus latency, both EBV and HCMV are closed, circular, nonintegrated intranuclear episomes; however, HHV6 is integrated into host cell DNA. ${ }^{2}$ EBV has a malignant potential and is associated with nasopharyngeal carcinoma, Burkitt's lymphoma, and AIDS-related lymphoproliferative disorder. Previous research has suggested and denied that herpesviruses are associated with myalgic encephalomyelitis (ME)/chronic fatigue syndrome (CFS). ${ }^{3-6} \mathrm{ME} / \mathrm{CFS}$ illness, like herpesviruses, is experienced worldwide, with over one million CFS sufferers in the US alone. ${ }^{5}$

Canonical evidence for herpesvirus not being the cause of ME/CFS is that there is no herpesvirus DNA-emia, herpesvirus antigenemia, or uniform serum immunoglobulin (Ig)M antibody increase to complete herpesvirus virion or increasing herpesvirus IgG serum antibody titers (Table 1). Nevertheless, we have developed a successful specific serum-cardiac biomarker diagnostic panel for herpesvirus subsetdirected treatment of CFS. ${ }^{6}$ Using this diagnostic panel, a systemic review of 142 CFS patients completing $\geq 6$ months of herpesvirus subset-directed antiviral therapy at a single treatment center from 2001 to 2007, including over 7000 patient visits and capturing over 35,000 fields of information, was analyzed. This study distinguished for 
Table I Comparative herpesvirus permissive and nonpermissive replication

\begin{tabular}{|c|c|c|}
\hline \multirow[t]{2}{*}{ Result } & \multicolumn{2}{|l|}{ Replication } \\
\hline & Permissive & Nonpermissive \\
\hline I. Pathogenic process & Necrosis of host cell and new infectious virus & Apoptosis of host cell, no new infectious virus \\
\hline 2. Circulation (blood and lymphatics) & $\begin{array}{l}\text { EBV (memory B-cell), HCMV (macrophage, } \\
\text { monocyte), HHV6 (T-cell) }\end{array}$ & None \\
\hline 3. DNA-emia & Yes & No \\
\hline 4. Antigenemia & Yes & No \\
\hline 5. IgM antibody to complete virus & Yes & No \\
\hline $\begin{array}{l}\text { 6. IgM antibody to nonstructural } \\
\text { gene products }\end{array}$ & No & Yes \\
\hline $\begin{array}{l}\text { 7. Serum IgG antibody titer to } \\
\text { complete virus }\end{array}$ & Yes, increasing & Yes, no increase in IgG titer \\
\hline $\begin{array}{l}\text { 8. Immediate-early virus gene } \\
\text { products }\end{array}$ & Yes & Yes \\
\hline $\begin{array}{l}\text { 9. Activation of late viral gene } \\
\text { products }\end{array}$ & Yes & Uncommon \\
\hline $\begin{array}{l}\text { 10. Therapeutic effect of specific } \\
\text { EBV, HCMV, HHV6 DNA } \\
\text { polymerase inhibitors }\end{array}$ & Yes (rapid) & $\begin{array}{l}\text { Yes (slow), prevents new host cell } \\
\text { recruitment (see Figure I) }\end{array}$ \\
\hline $\begin{array}{l}\text { 11. Proposed therapeutic effect of } \\
\text { specific EBV, HCMV, HHV6 } \\
\text { inhibitors of immediate-early } \\
\text { gene products }\end{array}$ & Yes (rapid) & Yes (rapid) \\
\hline 12. Clinical entities & $\begin{array}{l}\text { Infectious mononucleosis, myocarditis, } \\
\text { meningoencephalitis, polyneuropathy, } \\
\text { thyroiditis: enteritis, pneumonia, retinitis }\end{array}$ & ME/CFS, retinitis, interstitial pneumonia \\
\hline
\end{tabular}

Abbreviations: CFS, chronic fatigue syndrome; EBV, Epstein-Barr virus; HCMV, human cytomegalovirus; HHV6, human herpesvirus 6; Ig, immunoglobulin.

the first time two clinically identical ME/CFS groups, which we designate group A and group B. Among the $142 \mathrm{ME} / \mathrm{CFS}$ patients, 106 were group A patients and 36 were group $\mathrm{B}$ patients. Each of the $142 \mathrm{ME} / \mathrm{CFS}$ patients had elevated serum IgG antibody titers to EBV, HCMV, and/or HHV6 in single or multiple infections. The 106 group A ME/CFS patients had no co-infections, but group B CFS patients had co-infections with tick-borne Borrelia burgdorferi, Babesia microti, or Anaplasma (Ehrlichia) phagocytophila. Adult rheumatic fever was also an indistinguishable co-infection. After analysis of the $142 \mathrm{ME} / \mathrm{CFS}$ patients was completed, Mycoplasma pneumoniae was added to possible group B co-infections. ${ }^{6}$

A specific ME/CFS designed and validated Energy Index Point Score $\left(\right.$ EIPS $\left.^{\oplus}\right)$ monitored severity of ME/CFS illnesses every 3 months over the 72 months of the study. ${ }^{7}$ Group A $\mathrm{ME} / \mathrm{CFS}$ patients were treated with long-term valacyclovir for EBV ME/CFS subsets, or long-term valganciclovir for HCMV or HHV6 ME/CFS subsets. ME/CFS patients with both EBV and HCMV/HHV6 subsets were given both nucleosides. With the specific diagnostic panel determining antiviral therapy for the ME/CFS group and subset, 79 of the 106 group A ME/CFS patients (74.5\%) now continue normal lives $(P<0.0001) .{ }^{6}$ This is an unprecedented result.
Initially, ME/CFS patients had abnormal 24-h electrocardiography (ECG) recordings with resting tachycardias and abnormal left ventricular T-wave repolarizations, abnormal myocardial dynamics, and decreased left ventricular ejection fractions..$^{8-10}$ Accompanying symptoms were a pervasive life-altering fatigue, vasodepressive syncope, chest pains, fever, cervical lymphadenopathy, and muscle aches or joint pain. ${ }^{3}$ All of these findings improved or disappeared with long-term antiviral nucleosides. ${ }^{6}$ Resting standard 12-lead ECGs did not detect these cardiac abnormalities, which only became apparent with tachycardia. With antiviral therapy, elevated EBV, HCMV, HHV6 herpesvirus serum antibody titers fell. ${ }^{11-15}$ The mean EIPS of the 106 group A ME/CFS patients increased from baseline $<4$ to final $>6.5$, with a mean duration of antiviral treatment of 2.4 years. A former CFS patient (EIPS 4) with an EIPS of 6.5 can now fully participate in activities of normal living.

Surprisingly, after beginning valacyclovir/valganciclovir, the earliest time at which clinical improvement began was 6 months, which is far beyond what might customarily be expected. We offer a paradigm to explain both the absence of DNA-emia, antigenemia, and IgM antibody to complete virus and the long-time interval before ME/CFS patients begin recovery. 
Evidence that in the EBV subset, ME/CFS patients treated with long-term elevated EBVEA(D) and/or EBV, VCA IgM serum antibody titers valacyclovir decrease is shown in Table $2 .{ }^{10}$ Elevated EBVEA(D) serum antibody titers in $\mathrm{ME} / \mathrm{CFS}$ patients 1,4 , and 5 decreased with long-term valacyclovir. Similarly, in ME/CFS patients, 2, 3, and 6 with baseline elevated EBV, VCA IgM serum titers decreased. Elevated EBV, VCA IgM serum antibody titers are present in approximately $15 \%$ of EBV subset ME/CFS patients, and elevated EBV early antigen (EA)(D) serum titers are regularly present in EBV subset patients. ${ }^{14}$ Simultaneous myocardial dynamic studies of left ventricular ejection fractions showed a co-occurring increase in left ventricular ejection fractions with a mean value of +10.8 units $(+18.9 \%), P=0.007$. The EIPS for these same six EBV ME/CFS patients improved from 3.7 to $6.5, P=0.003$. Tachycardias at rest, abnormal oscillating T-wave flattenings and inversions with 24-h ECG monitoring, and multiple symptoms improved with long-term valacyclovir. ${ }^{10-14}$ Among the 106 group A ME/CFS patients followed for at least 6 months in 2001-2007, there were $42.5 \%$ with single herpesvirus EBV, HCMV, or HHV6 subsets and $57.5 \%$ with multiple herpesvirus ME/CFS. ${ }^{6}$ Single and multiple ME/CFS patients responded equally.

Valacyclovir and valganciclovir inhibit viral EBV, HCMV, or HHV6 replication by inhibiting the core proteins, DNA polymerase, and thymidine kinase, which occupy approximately the 50th gene of the early, middle, and late sequential cascade of the several hundred herpesvirus genes in each of the three genomes. The murine retrovirus XMRV may compromise immune function in ME/CFS patients, facilitating nonpermissive herpesvirus replication. ${ }^{16,17}$ We suggest that in ME/CFS patients, valacyclovir and valganciclovir inhibit the herpesvirus lytic replication cycle and thus prevent "recruitment of new host cells to ME/CFS patients" and indirectly inhibit nonpermissive virus replication, thereby facilitating recovery from $\mathrm{ME} / \mathrm{CFS}$ illness ${ }^{18}$ (Table 1, Figure 1).

We propose that ME/CFS patients have nonpermissive herpesvirus (EBV, HCMV, HHV6) replication, expressing immediate-early (IE) gene products, which induce host cell dysregulation and host cell apoptosis. ${ }^{19,20}$ At biopsy in ME/CFS patients, cardiac muscle fiber apoptosis is present, but EBV and HCMV polymerase chain reactions for complete virus are negative. ${ }^{21}$

The three earliest genes expressed during initiation of the EBV lytic cycle are the IE genes zta (BZLF1 and EB1), Rta (R and BRLF1), and Mta (SM, BMLF1, and EB2). These early genes and their proteins $\mathrm{Z}$ (ZEBA, Zta, EBI) are essential for EBV lytic replication. The EBNA-2 gene is anti-apoptotic, favoring progression of the lytic cycle; therefore, serum assays for this late gene product are not included in the ME/CFS diagnostic profile. ${ }^{6,14,22}$ The Zta IE gene product induces apoptosis with activation of many cellular proteolytic enzymes. Zta binds with high affinity to cellular AP-1 sites, altering host cell signaling and inducing IL-6, IL-10, TGFß, the tyrosine kinase TKT, matrix metalloproteinases (MMPI and MMP-9) c-Fos, and the early growth response (EGR-1). IL-10 and TgFß suppress host immune responses. In infected and uninfected cells, EBV Zta is taken up and directed to the nucleus, activating apoptosis. Zta inhibits IL-10, decreasing macrophage and NK cell functions, NK and T-cell mediated cytotoxic responses, MHC class I molecules and immune presentations of lytic viral antigens, and major tumor necrosis factor alpha receptor (TNF-R1). Zta minimizes responses to TNF-receptor-mediated apoptosis signaling interferons. Zta mitigates the innate adaptive immune responses to EBV reactivation. Zta mediates these signaling events without EBV gene progression to the lytic

Table 2 Phase II: valacyclovir treatment in six CFS patients with single-virus EBV infections (EBV antibody titers in serum)

\begin{tabular}{|c|c|c|c|c|c|c|c|c|c|c|c|}
\hline \multicolumn{5}{|c|}{ Left ventricular ejection fraction (units) } & \multicolumn{2}{|c|}{$\begin{array}{l}\text { Viral capsid } \\
\text { antigen, IgM }\end{array}$} & \multicolumn{2}{|c|}{ Early antigen } & \multicolumn{3}{|c|}{ Energy index point score } \\
\hline Patient & Pre & Post* & Change* & $\% *$ & Pre & Post* & Pre & Post* & Pre & Post & Change \\
\hline I & 59 & 67 & +8 & +13.6 & Neg & $\mathrm{Neg}$ & $>320$ & 320 & 5 & 8 & +3 \\
\hline 2 & 59 & 76 & +17 & +29 & 142 & $<10$ & Neg & Neg & I & 3 & +2 \\
\hline 3 & 70 & 75 & +5 & +7 & 228 & 39 & 40 & 80 & 3 & 7 & +4 \\
\hline 4 & 56 & 76 & +20 & +36 & $\mathrm{Neg}$ & $\mathrm{Neg}$ & 20 & $\mathrm{Neg}$ & 5 & 8 & +3 \\
\hline 5 & 51 & 59 & +8 & +16 & $\mathrm{Neg}$ & $\mathrm{Neg}$ & 320 & 40 & 4 & 5 & +1 \\
\hline 6 & 58 & 65 & +7 & +12 & 110 & $<10$ & $\mathrm{Neg}$ & $\mathrm{Neg}$ & 4 & 8 & +4 \\
\hline \multirow[t]{2}{*}{ Mean } & 59 & 70 & +10.8 & 18.9 & & & & & 3.7 & 6.5 & +2.8 \\
\hline & & \multicolumn{3}{|c|}{$P=0.007$} & & & & & \multicolumn{3}{|c|}{$P=0.003$} \\
\hline
\end{tabular}

Notes: *Studies performed after 6 months of valacyclovir treatment. Copyright @ 2002, Drugs Today. Reprinted with permission from Lerner AM, Beqaj SH, Deeter HJ, et al. A six-month trial of valacyclovir in the Epstein-Barr virus subset of chronic fatigue syndrome: improvement in left ventricular function. Drugs Today. 2002;38:549-56I. Abbreviations: CFS, chronic fatigue syndrome; EBV, Epstein-Barr virus; Ig, immunoglobulin. 


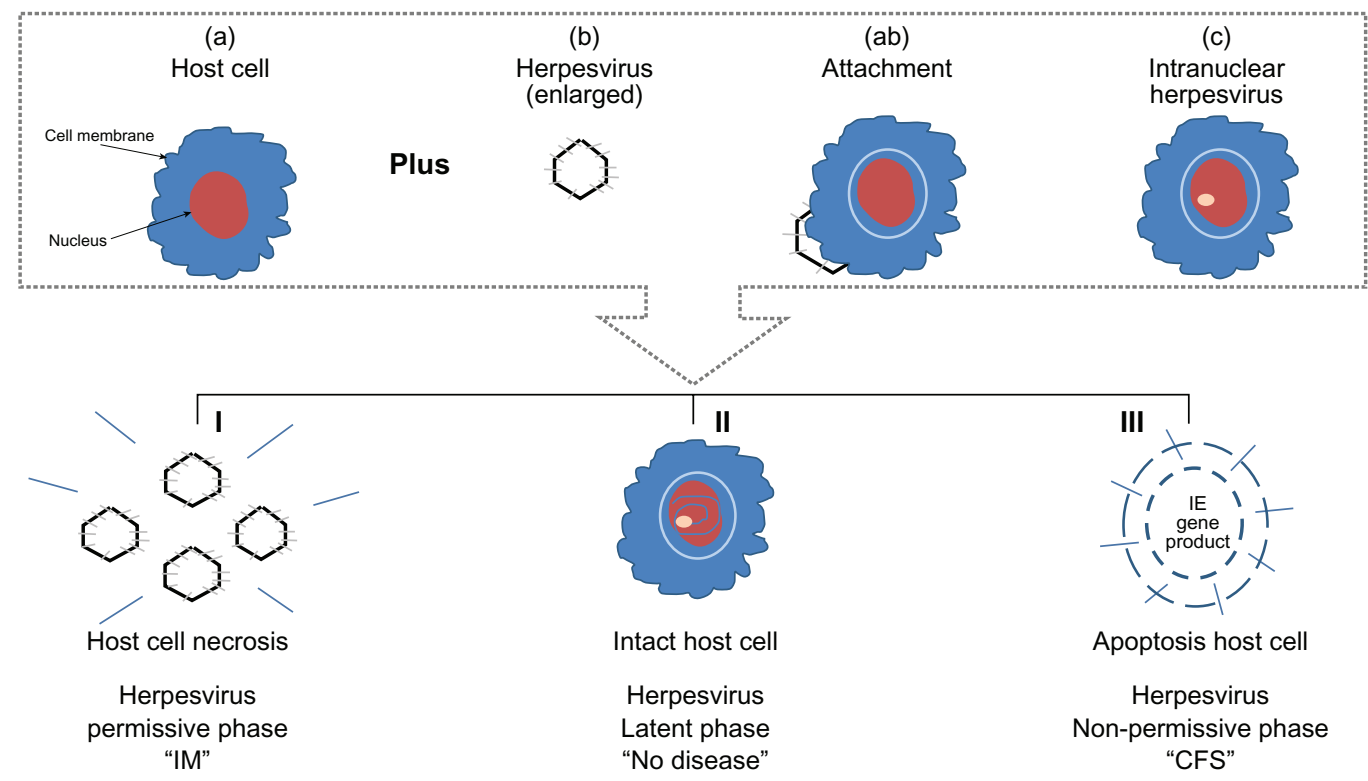

Figure I During the proposed three phases of herpesvirus replication (a) host cell and (b) herpesvirus bind at the cytoplasmic membrane (ab) and (c) herpesvirus transits intranuclearly. Permissive herpesvirus replication yields I) new virus and host cell necrosis infectious mononucleosis; II) the latent herpesvirus phase preserves both the virus genome and the healthy host cell; III) nonpermissive herpesvirus replication yields host cell apoptosis no new virus and ME/CFS.

Abbreviations: CFS, chronic fatigue syndrome; ME, myalgic encephalomyelitis.

cascade. ${ }^{23-31} \mathrm{ME} / \mathrm{CFS}$ illness may require herpesvirus IE gene product-induced apoptosis with associated cellular dysregulation and proteolysis without virus lytic cycle completion and new infectious herpesvirus. Herpesvirus nonpermissive replication may also be a pathogenic mechanism in HCMV interstitial pneumonia where virus recovery in the lung does not correlate with virus titers in affected tissues. ${ }^{32-34}$

In the ME/CFS patient, EBV, HCMV, and HHV6 herpesviruses may enter host cells and initiate IE gene products, host cell dysregulation, cellular proteolysis, and inhibition of the immune response and apoptosis. No infectious new virus results. ME/CFS illness is consistent with herpesvirus IE gene product nonlytic-induced apoptosis. Valacyclovir and valganciclovir inhibit new host cell herpesvirus recruitment and, ultimately, herpesvirus IE-induced host cell apoptosis. ME/CFS clinical recovery follows. ${ }^{6,14}$ Direct anti-ME/CFS therapy may be inhibition of EBV, HCMV, and HHV6 IE gene expression with drugs such as the antisense oligonucleotide ISIS 2922. ${ }^{35,36}$ Kogelnik et al have described the therapeutic effect of valganciclovir in ME/CFS patients with HHV6 subset CFS, and Klimas and O'Brien have summarized inflammatory immune functions in ME/CFS that are compatible with the host cell dysregulation we propose. ${ }^{37-39}$

Further evidence for IE-induced pathology and nonpermissive replication in the EBV subset $\mathrm{ME} /$ CFS parallel to that in the HCMV subset ME/CFS (eg, p52 and $\mathrm{CM}_{2}$ ) is the work of Glaser, Williams, and colleagues. ${ }^{11,12,40-44}$ EBV ME/CFS subset patients also have uniquely elevated serum antibody titers to the nonstructural gene products EBV-specific DNase and DNA polymerase. These elevated EBV-specific serum antibody titers are also present in patients with EBV-related malignancies, Burkitt's lymphoma, and nasopharyngeal carcinoma, but are not present in patients with infectious mononucleosis or in healthy individuals. The EBV-EA(D) encodes for at least six different virus enzymes, including deoxyuridine triphosphate nucleotidohydoxylase (dUTPase). This early gene product, like HCMV, IE, and $\mathrm{IE}_{2}$, induces activation of proinflammatory cytokines through NK-K6, demonstrating that EBV dUTPase is a pathogen-associated molecule and that it has immunomodulator functions. Direction of antiviral therapy toward inhibition of IE genes of EBV, HCMV, and HHV6 may well shorten the time for ME/CFS recovery using the nucleosides valacyclovir and valganciclovir, which inhibit only the DNA polymerases and thymidine kinases of these herpesviruses that are present at a relatively mid-gene location in these large genomes.

\section{Acknowledgments}

We gratefully appreciate Deanna Mason and Deborah McNeilance, transcriptionists. We recognize and thank Leonard A Jason, Center for Community Research, DePaul University, Chicago, Illinois, USA; James Edington (for Figure 1 and Table 1), Ann Cavanagh, and Ken Gill, of the Dr A Martin Lerner CFS Foundation, for critical review of this manuscript. 


\section{Disclosure}

There was no grant or pharmaceutical support. Drs Lerner and Beqaj have financial interests in CFS LLC, which owns patents for the diagnosis and treatment of CFS with antiviral agents. More information is available at http://www.treatmentcenterforCFS.com.

Presented in part at Science Day, Chronic Fatigue Syndrome Advisory Committee, National Institutes of Health, October 12, 2010, Washington, DC, USA.

\section{References}

1. Roizman B. The family of herpes viridae: A brief introduction. In: Roizman B, Whitley RJ, Lopez C, editors. The Human Herpes Viruses. New York. Raven Press; 1993:1-10.

2. Arbuckle JH, Medverczky MM, Luka J, et al. The latent human herpesvirus-6 A genome specifically integrates in telomeres of human chromosomes in vivo and in vitro. Proc Natl Acad Sci U S A. 2010; 107:5563-5568.

3. Fukuda K, Straus SE, Hickie I, Sharp MC, Dobbins JG, Komaroff A. The chronic fatigue syndrome: a comprehensive approach to its definition and study. International Chronic Fatigue Syndrome Study Group. Ann Intern Med 1994;121:953-959.

4. Soto NE, Straus SE. Chronic fatigue syndrome and herpesviruses: the fading evidence. Herpes. 2000;7:46-50.

5. Jason LA, Richman JA, Rademaker AE, et al. A community-based study of chronic fatigue syndrome. Arch Intern Med. 1999;159: 2129-2137.

6. Lerner AM, Beqaj S, Fitzgerald JT, et al. Subset-directed antiviral treatment of 142 herpesvirus patients with chronic fatigue syndrome. Virus Adapt Treat. 2010;2:1-11.

7. Lerner AM, Beqaj SH, Fitzgerald JT. Validation of the Energy Index Point Score to serially measure degree of disability in patients with chronic fatigue syndrome. In Vivo. 2008;22:799-802.

8. Lerner AM, Goldstein J, Chang $\mathrm{CH}$, et al. Cardiac involvement in patients with the chronic fatigue syndrome as documented with Holter and biopsy data in Birmingham, Michigan. Infect Dis Clin Prac. 1997; 6:327-333.

9. Dworkin HJ, Lawrie-Hoppen C, Bohdiewiez P, et al. Abnormal left ventricular myocardial dynamics in eleven patients with the chronic fatigue syndrome. Clin Nuc Med. 1994;19:657-677.

10. Lerner AM, Beqaj SH, Deeter HJ, et al. A six-month trial of valacyclovir in the Epstein-Barr virus subset of chronic fatigue syndrome: improvement in left ventricular function. Drugs Today. 2002;38: 549-561.

11. Beqaj SH, Lerner AM, Fitzgerald JT. Immunoassay with cytomegalovirus early antigens from gene products p52 and $\mathrm{CM}_{2}$ (UL44 and UL57) detects active infection in patients with chronic fatigue syndrome. J Clin Path. 2008;61:623-626.

12. Lerner AM, Beqaj SH, Deeter HJ, et al. IgM serum antibodies to human cytomegalovirus nonstructural gene products p52 and CM2 (UL44 and UL57) are uniquely present in a subset of patients with chronic fatigue syndrome. In Vivo. 2002;16:153-160.

13. Lerner AM, Beqaj SH, Deeter RG, et al. IgM serum antibodies to Epstein-Barr virus are uniquely present in a subset of patients with chronic fatigue syndrome. In Vivo. 2004;18:101-106.

14. Lerner AM, Beqaj S, Gill K, Edington J, et al. An update on the management of glandular fever (infectious mononucleosis) and its sequelae caused by Epstein-Barr virus (HHV-4): New and emerging treatment strategies. Virus Adapt Treat. 2010;2:1-11.

15. Lerner AM, Dworkin HJ, Sayyed T, et al. Prevalence of abnormal cardiac wall motion in the cardiomyopathy associated with incomplete multiplication of EBV and/or CMV in patients with chronic fatigue syndrome. In Vivo. 2004;18:417-424.
16. Lombardi VC, Ruscetti FW, Das Gupta J, et al. Detection of an infectious retrovirus, XMRV, in blood cells of patients with chronic fatigue syndrome. Science. 2009;326(5952):585-589.

17. Lo SC, Pripuzova N, Li B, et al. Detection of MLV-related virus gene sequences in blood of patients with chronic fatigue syndrome and healthy blood donors. Proc Natl Acad Sci. 2010;107:15874-15879.

18. Straus SE. Epstein-Barr virus and human herpesviruses 6 and 7. In: Gallasso GT, Whitley RJ, Merigan TC, editors. Antiviral Agents and Human Viral Diseases. Lippincott-Rave Publishers. Ch 18:708.

19. Landolfo S, Gariglio G, Lembo D. The human cytomegalovirus. Pharmacol Therap. 2003;98:269-297.

20. Puchtler E, Stamminger T. An inducible promoter mediates abundant expression from the immediate-early 2 gene region of human cytomegalovirus at late times after infection. J Virol. 1991; 65:6301-6306.

21. Lerner AM, Zervos M, Dworkin HJ, et al. A new cardiomyopathy: a pilot study of intravenous ganciclovir in a subset of chronic fatigue syndrome. Inf Dis Clin Prac. 1997;16:110-117.

22. Israel BF, Kenney SC. EBV lytic infection. In: Robertson ES, editor. Epstein-Barr virus. Norfolk, England: Caister Academic Press; 2005:571-611.

23. Sinclair J, Sissons P. Latency and reactivation of human cytomegalovirus. J Gen Virol. 2006;87:1763-1779.

24. Knight JS, Robertson ES. Epstein-Barr virus and the cell cycle. In: Robertson ES, editor. Epstein-Barr virus. Norfolk, England: Caister Academic Press; 2005:501-532.

25. Chevallier-Greco A, Manet E, Chavier P, Mosnier C, Daillie J, Sergeant A. Both Epstein-Barr virus (EBV)-encoded trans-acting factors, EBI and EB2 are required to activate transcription from an EBV early promoter. Embo J. 1986;5:3243-3249.

26. Countryman J, Miller G. Activation of expression of latent Epstein-Barr herpesvirus after gene transfer with a small cloned subfragment of heterogenous viral DNA. Proc Natl Acad Sci U S A. 1985:4085-4089.

27. Rooney CM, Rowe D, Ragot T, et al. The spliced BZLF1 gene of Epstein-Barr virus (EBV) transactivates an early promoter and induces the virus productive cycle. J Virol. 1989;63:3109-3116.

28. Ragoczy T, Miller G. Autostimulation of the Epstein-Barr virus BRLF1 promoter is mediated through consensus SP1 and SP3 binding sites. J Virol. 2001;75:5240-5251.

29. Takada K, Ono Y. Synchronous and sequential activation of latently infected Epstein-Barr virus genomes. J Virol. 1989;63:445-449.

30. Takada K, Shimizu N, Sakuma S, et al. Transactivation of the latent Epstein-Barr virus (EBV) genome after transfection of the EBV DNA fragment. J Virol. 1986;57(3):1016-1022.

31. Zalani S, Holley-Guthrie E, Kennedy S. The Zif268 cellular transcription factor activates expression of the Epstein-Barr virus immediate-early BRLF1 promoter. J Virol. 1995;69:3816-3823.

32. Shanley JD, Pesanti EL. The relation of viral replication to interstitial pneumonitis in murine cytomegalovirus lung infection. J Infect Dis. $1985 ; 151: 454-458$.

33. Forman SJ, Zaia JA. Treatment and prevention of cytomegalovirus pneumonia after bone marrow transplantation: where do we stand? Blood. 1994;1:2392-2398.

34. Meier JL, Stinski MF. Regulation of human cytomegalovirus immediate-early gene expression. Intervirology. 1996;39:331-342.

35. Scholz M, Doerr HW, Cinatl J. Inhibition of cytomegalovirus immediate early gene expression: a therapeutic option? Antiviral Res. 2001;49:129-145.

36. Cinatl J Jr, Kotchetkov R, Weimer E, et al. The antisense oligonucleotide ISIS 2922 prevents cytomegalovirus-induced upregulation of IL-8 and ICAM-1 in cultured human fibroblasts. J Med Virol. 2000; 60(3):313-323.

37. Kogelnik AM, Loomis K, Hoegh-Petersen M, et al. Use of valganciclovir in patients with elevated antibody titers against Human Herpesvirus-6 (HHV-6) and Epstein-Barr Virus (EBV) who were experiencing central nervous system dysfunction including long-standing fatigue. $J$ Clin Virol. 2006;37:S33-S38. 
38. Eizuru Y, Minamishimu Y. Evidence for putative immediate early antigen in human herpesvirus-6 infected cell. J Gen Virol. 1992; 73:2161-2165.

39. Klimas NG, O’Brien K. Chronic fatigue syndrome: inflammation, immune function and neuroendocrine interactions. Curr Rheumatol Reports. 2007;9:482-487.

40. Jones JF, Williams M, Schooley RT, et al. Antibodies to Epstein-Barr virus-specific DNase and DNA polymerase in the chronic fatigue syndrome. Arch Intern Med. 1988;148:1957-1960.

41. Cheng Y, Chen J, Glaser R, et al. Frequency and levels of antibodies to Epstein-Barr virus-specific DNase are elevated in patients with nasopharyngeal carcinoma. Proc Natl Acad Sci U S A. 1980; 77(10):6162-6165.
42. Tsai C, Williams M, Glaser R. A monoclonal antibody that neutralizes Epstein-Barr virus DNA polymerase activity. Intervirology. 1990; $31(2-4): 215-222$

43. Padgett DA, Hotchkiss AK, Pyter LM, et al. Epstein-Barr virus-encoded dUTPase modulates immune function and induces sickness behavior in mice. J Med Virol. 2004;74(3):442-448.

44. Ariza M, Glaser R, Kaumaya P, et al. The EBV-encoded dUTPase activates NF-kappaB through the TLR2 and MyD88-dependent signaling pathway. J Immonol. 2009;182(2):851-859.

\section{Publish your work in this journal}

Virus Adaptation and Treatment is an international, peer-reviewed open access journal focusing on the study of virology, viral adaptation and the development and use of antiviral drugs and vaccines to achieve improved outcomes in infection control and treatment. The journal welcomes original research, basic science, clinical \& epidemiological studies, reviews \& evaluations, expert opinion and commentary, case reports and extended reports. The manuscript management system is completely online and includes a very quick and fair peer-review system, which is all easy to use. Visit http://www.dovepress.com/testimonials.php to read real quotes from published authors.

Submit your manuscript here: http://www.dovepress.com/virus-adaptation-and-treatment-journal 